Journal of Engineering and Applied Sciences 14 (7): 2152-2157, 2019

ISSN: 1816-949X

(C) Medwell Journals, 2019

\title{
A Study on the Crime Investigation using Human Foot Sound Analysis
}

\author{
${ }^{1} \mathrm{Ik}-$ Soo Ahn, ${ }^{1}$ Myung-Jin Bae and ${ }^{2}$ Seong-Geon Bae \\ ${ }^{1}$ Department of Information and Telecommunication, Soongsil University, \\ 369 Sangdo-ro, Dongjak-gu, Seoul, Korea \\ ${ }^{2}$ School of Software Application, Kangnam University, Gyunggido, Korea
}

\begin{abstract}
As footstep sound collected in a crime scene can imply circumstances of the scene as well as information about the criminal itcould be the key to solving the problem. This may also include gender and identification of the person, psychological status and situation, place and time, even weather and seasons. What is more, each footstep has its own unique features which helps to increase possibility of recognizing criminals by their acquaintances when suspects are listed. Individual footstep contains different stories inside and thus itimplies that it can be a key clue to problem solving if any recorded footstep sound exists. This research tries to help prevent and settle a crime by thoroughly analyzing information inside individual footstep.
\end{abstract}

Key words: Footstep sound, crime scene, information, solving the problem, key clue to problem solving, help

\section{INTRODUCTION}

In modern society, new crimes appear and are becoming more and more intellectualized. We can know how serious it is from the research report showing that the number of unsolved crimes every year is increasing. Furthermore, cruel and violent crimes such as a hate crime aiming at unspecified people who have no causal relationship are so common that many people are becoming anxious. Of course, technologies of preventing and investigating those crimes have developed quickly as well but the reality is that criminal technique is changing, so, fast that investigators are busy following them. For the future investigation techniques, there should a foundation where crimes can be predicted based on biotechnology and psychoanalysis. Along with this, this research attempted to study how to identify criminal by analyzing footsteps to find identification, psychological status, criminal scene of the crime in relation to crime prevention and solving based on the sound.

\section{MATERIALS AND METHODS}

Research footstep: Footstep sound in crime scene has various information for solving the problem. Through its sound, we can estimate criminal's identification, personal characteristics, overall environment and psychological status at the time. For footstep analysis used to settle the crime, this research carried out study in two perspectives, situation analysis based on personal characteristics and footstep texture and psychological status based on rhythm of the footstep.
Analysis by type of shoe: Types of shoes can tell the person's identification such as gender, age and job. First of all, the sound of suit shoes or heel implies that the person is a grown up and may work for a company. Generally, gender is told by sound of shoes, usually men has this "plodding" walking and women has "tapping" sound. Of course, both may wear casual trainers or special mountain shoes on weekends or holidays going for exercising or climbing. If one prefers casual attire, he/she may wear casual shoes as well. Even on weekends or holidays, one may wear formal suit and shoes for wedding or certain events (Yoo, 2016; Go and Kim, 1997; Ahn, 2012; Kang and Jeong, 2007; Ryu and Chang, 2004).

Therefore, situation is a key factor that should be considered. To have a very basic comparisons, this research has selected adults working in an office as its models and analyzed characteristics of their footstep sounds. Figure 1 and 2 is a graph showing footsteps of male and female workers based on different types of shoes. As a result, plodding and low sound made from men's shoes tends to be in low frequency range with a high energy and bandwidth across the whole range compared to that of sound from women's high heels. Other types of shoes used for analysis are trainers, climbing shoes, boots, rubber boots and slippers. As these types of shoes cannot tell clearly the gender, age and job of the person, weight, depth and stride have to be considered in the study. Light footstep sound with a narrow width and a small amount of touch imply that the person is young. For boots and climbing shoes, no clear characteristics of gender can be shown. As they have the

Corresponding Author: Myung-Jin Bae, Department of Information and Telecommunication, Soongsil University, 369 Sangdo-ro, Dongjak-gu, Seoul, Korea 


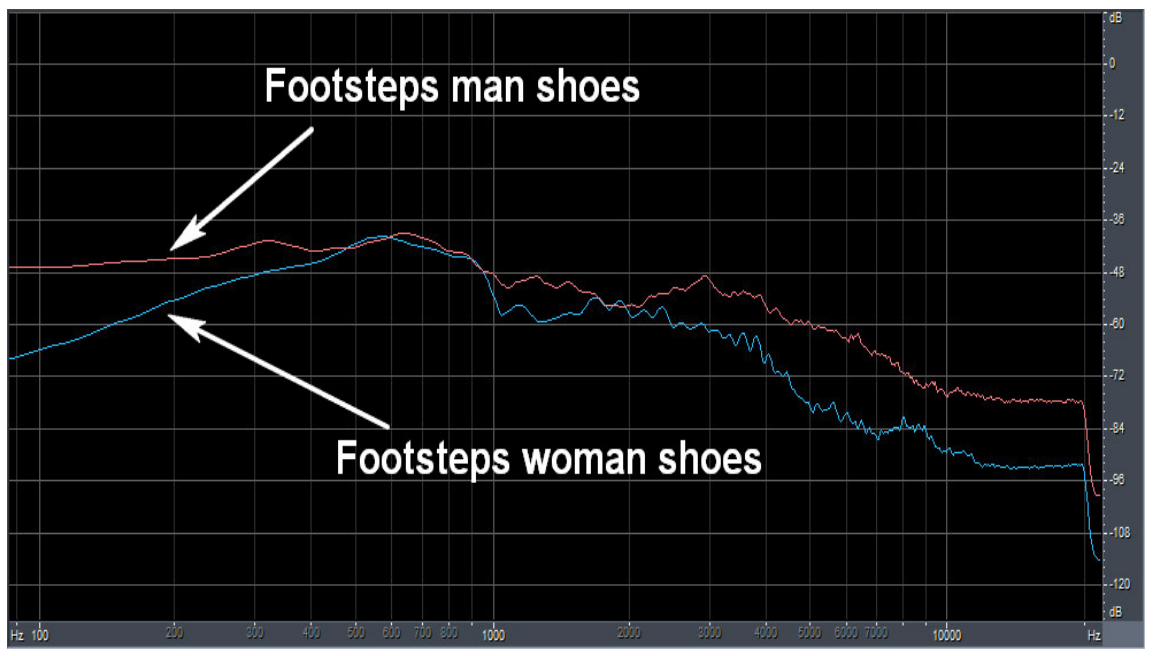

Fig. 1: Men and women shoes footsteps comparison spectrum graph

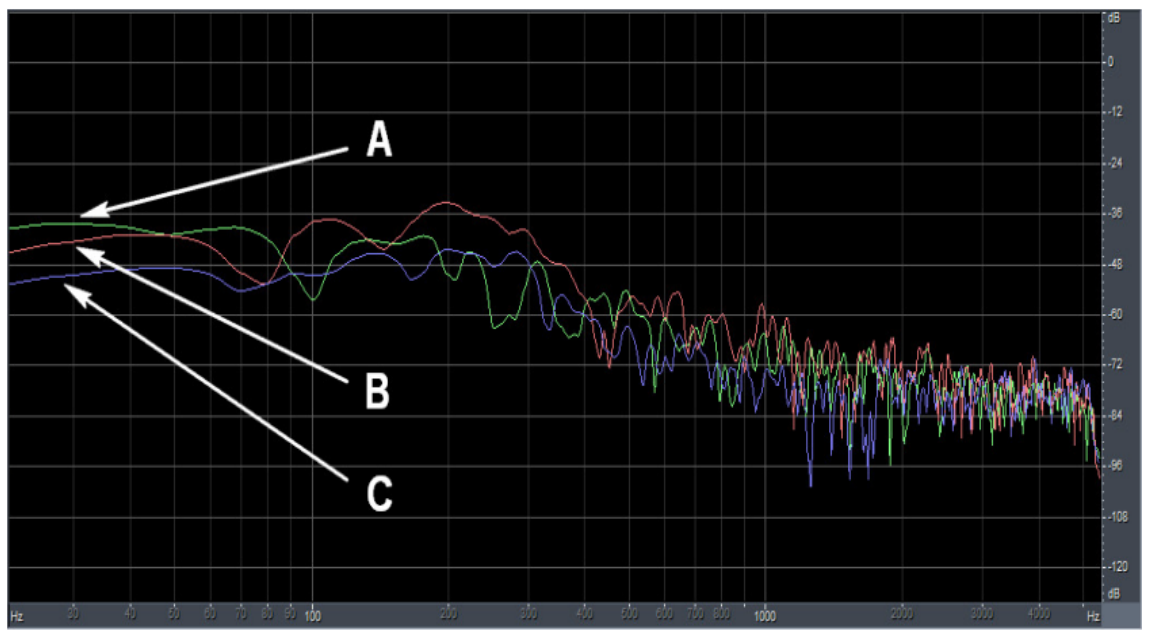

Fig. 2: Comparison graph of the difference between characteristics footstep sounds

similar tone, various information such as weight and stride have to be analyzed as well. For example, if the location is close to military, we can tell from the footstep sound made from military boots and if for climbing shoes, we can determine it to be climbing shoes. In terms of gender, this can be recognized by weight and depth of the footstep.

Analysis by walking habits: If age and identification are recognized from types of shoes, we can also identify individual characteristics from their walking habits. Different footstep sounds are made depending on the person's gait, out-toe gait or a person tend to walk faster than others. Also, depending on the habit, area of bottom part of shoes touching the ground also varies and thus, this makes a different footstep sound. Along with this, rhythm of footstep and energy as well as stride are combined to create one's unique characteristics. If footstep analysis is done by having a close observation on above factors, subject of footstep can be shaped up in more details. This is possible because each person has different taste of shoes, stride, rhythm, walking gait and energy applied to the ground when walking. Therefore, footstep is unique to the person and thus, it can be used as a tool for identifying a person like fingerprint. For families or colleagues who have been with the person for a long time, they can easily figure out footstep characteristics. If footstep sound in crime scene is recorded and people around the area listens to the sound and identify it itis easy to recognize the person. If footstep sounds of criminals are recorded and made into a database, this will also provide an easy way to 


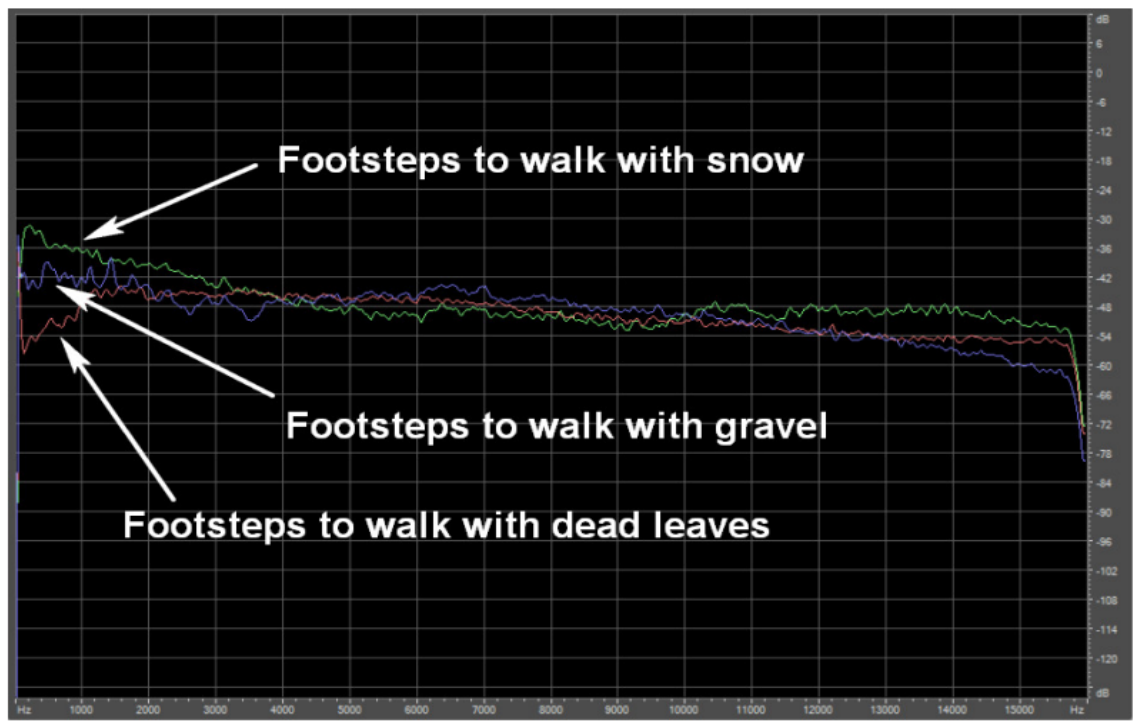

Fig. 3: Environment analysis comparison graph by footsteps sound

solve the problem by comparing recorded footstep with the database. Individual footstep is comprehensively and comparatively analyzed by time domain graph, spectrum graph and spectrogram graph. The time domain graph shows amplitude and period by time, spectrogram showing rhythm shows energy and tone of footstep and lastly, spectrum provides data for analyzing characteristics of amplitude by each frequency scope.

Analysis of the bottom surface: Space analysis is done by examining condition of floor area creating footstep sound. This enables identification of location where subject of footstep was. This footstep not only tells us types of shoes but also information for estimating condition of the ground. Clear footstep sound that means no impurities such as sand and one that is made from a well-cleaned indoor space has the best information for identifying the person. This is because clear sound makes it easier to recognize the person and thus, helps a lot with finding suspects.

As outdoor areas have their unique features and footstep sound made from this space is mixed with environmental noise, we can analyze environment of the space from texture of the sound made from the shoes. The texture of footstep can be compared through spectrum graph. Even though indoor space has a perfect noise protection, regardless of the size, each space has its unique room tone and it may have noise or music or even small noise from far outside. Also, depending on the texture of the floor such as marble, carpet or wooden floor, footstep sound differs. As this is the case by having a detailed attention to texture and surrounding noise, we can guess the location. However, outdoor sounds include wind sound along with noise from residents, road noise, sellers if in a market and even suburb areas, there is a louder noise from birds which is heard small inside the city. In rural areas, there is a harmony of beautiful nature sounds made up of birds, wind, twig, stream and valley. Even footstep sound differs depending on the changes in space. For instance, sound from city tends to have walking road block or asphalt sounds but rural roads tend to have louder sand sounds. If, we walk in the forest, we will hear more grass sound with rocks. For beach or sand areas, there will be a different sound made from sand or small rocks. Also, outdoor sound is very different from weather and season. Therefore, we can find a clue if we look at this in more details. For instance, sound of stepping on leaves will be made in fall and sound of walking on snow will be made in Winter. Of course, even if the season is fall, we will not only hear the sound of stepping on the leaf. Also itdoes not always snow in Winter. However, they can be a good clue for figuring out the season. Figure 3 shows sound made from walking on the snow. We can confirm that it snowed on the day and it is Winter season and shows sound made from walking on gravels. This shows that the person is somewhere around the riverside, beach area or gravel collectin areas. Figure 3 shows sound from walking on the leaves, thus, we can say that it is fall season and area should be park, forest or in the mountain where lot of leaves are accumulated on the ground. Consequently, depending on the types of ground where sound is made, we can have space and environmental analysis for finding out the space and season (Fig. 4). 
(a)

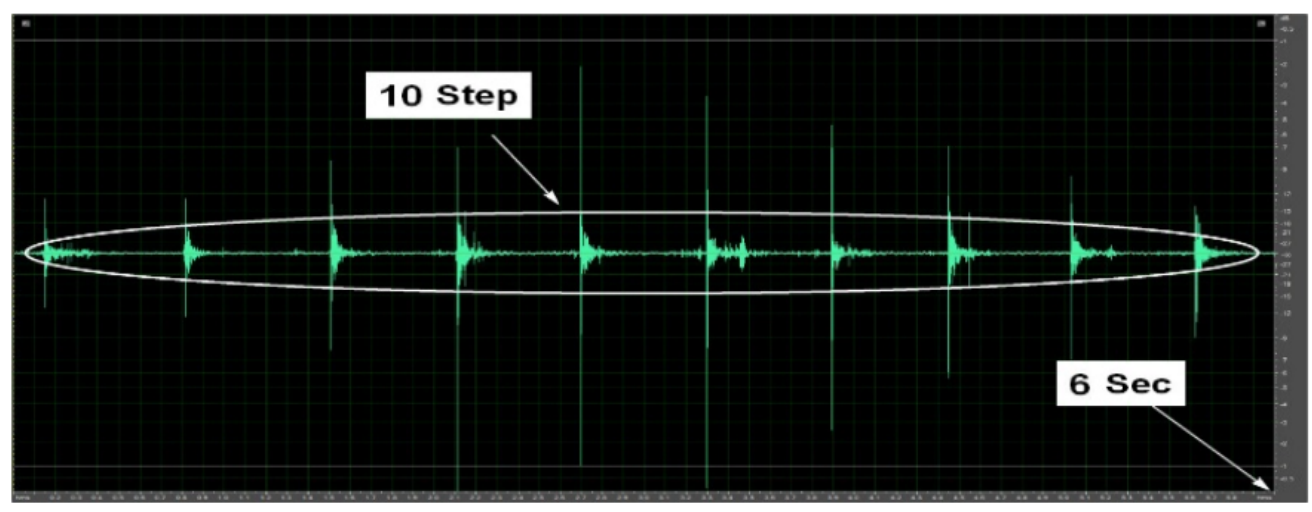

(b)

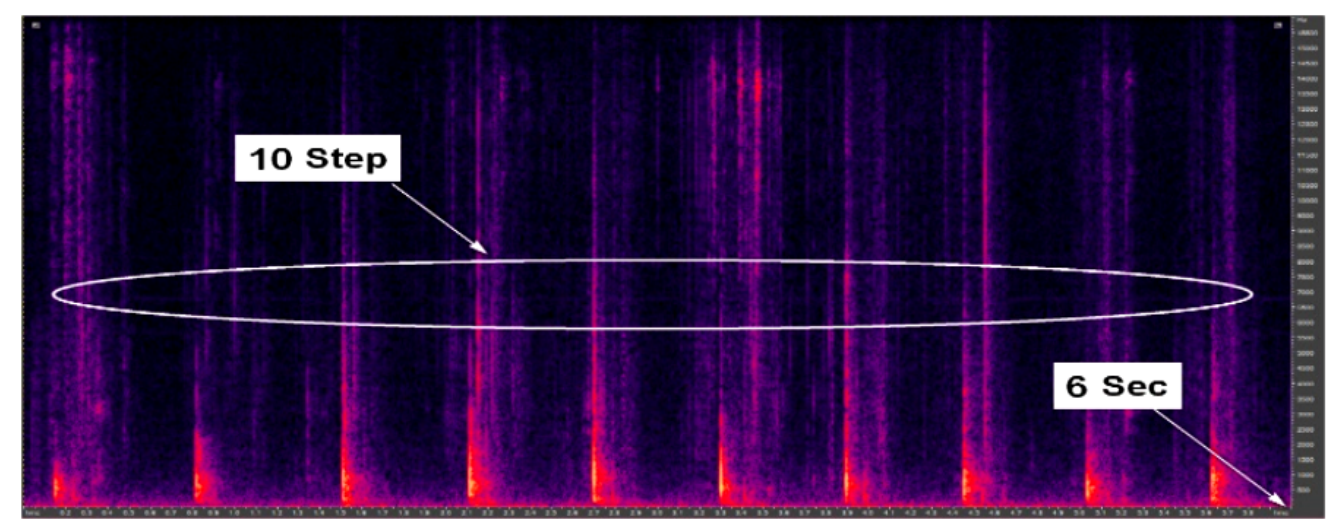

(c)

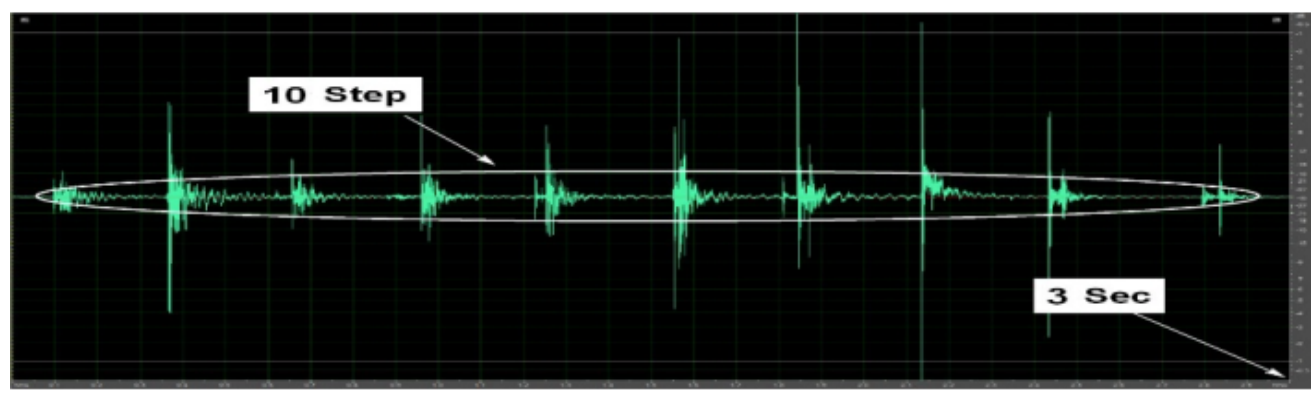

(d)

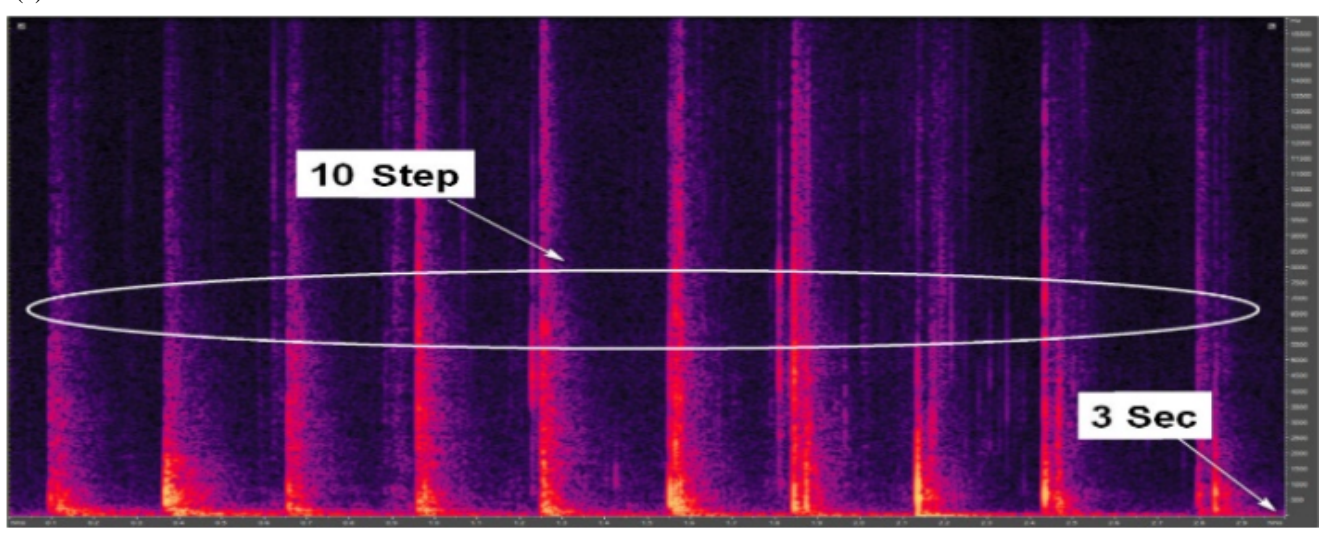

Fig. 4: a-d) Individual comparing analysis of the context by footsteps sound 
Analysis by speed changes and regularity: Analysis on changes in speed and regularity of footstep sound can show psychological status of the person. Among various information contained in the footstep, personal emotion is also included. This personal information is in large, divided into happiness, sorrow, pain and joy. It tells psychological status of the person when compared with the normal walking stride. Ones that tend to be faster or running sounds means that the person is in a hurry and in contrast, walking gait with no energy or slow means that the person is either tired or in a bad mood. Also, gait after drinking is very unstable and irregular, meaning that the person is drunk or failed to walk straight. Figure 4 of walking and running sounds contain two very important information. First of all, time domain graph shows that walking sound of a has 10 steps in 6 sec but running sound of b has 10 steps in $3 \mathrm{sec}$, twice much more. Also, spectrogram shows overall step of a has strong energy in low frequency scope. We can see that first stepping part has the strong energy and the point where foot is lifted up has a low energy in a repeating cycle. Compared to this, running sound of $\mathrm{b}$ has strong energy across the overall scope. Those steps tend to make repeating strong energy. From this, we can figure out walking and running footstep sounds and make them into a database (Se-Bin, 2014; Soon-Hee, 2015; Kyu-Young and Yun-Hee, 2014; Hoon and Myung, 2007; Jung and Bae, 2007; Buhm et al., 2012; Bae and Kim, 2013).

\section{RESULTS AND DISCUSSION}

Criminal investigation techniques based on analysis by footstep sounds: To solve the crime with footstep sounds, we have to turn different analysis obtained from collected sounds into a database and carry out investigation based on this.

Recording footsteps: There must be clear evidences in the crime scene. The fact is that we just cannot find it. Even hair, sweat, dandruff and dust can be the clue. However, there are cases with permanently unsolved due to lack of evidences found in initial investigation. To overcome this dilemma, we have to find different tools for finding evidence. To apply investigation technique mentioned in this research to the case settlement, footstep recording devices should be installed in addition to different security devices or present recorders should be well-utilized.

Today, even CCTVs have built-in recording and speaker devices, so that, surrounding noise can be recorded and alert sound or notice can be made by person with movie delivered in real-time. Other devices include personal portable recorder, recording application in

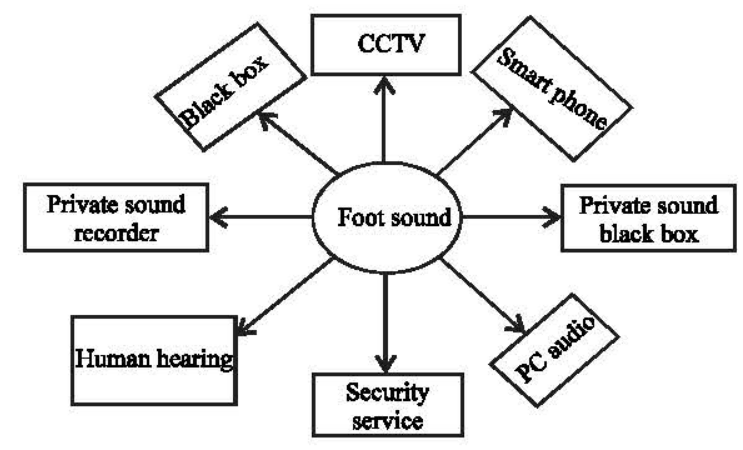

Fig. 5: Overview footstep sounds collection device

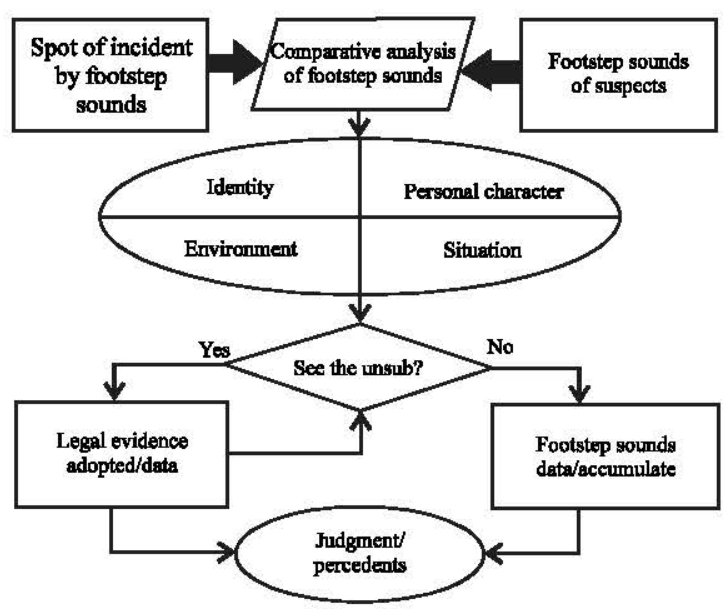

Fig. 6: Criminal investigation techniques flowchart by footstep sounds

smartphone, car black box, personal black box, recording function in computer and recording in security devices. The most important tool is hearing ability of a person. This is because one who identifies footstep by hearing will play a key role in finding the suspect (Fig. 5).

Criminal investigation techniques by footsteps: We should establish a new investigation technique by thoroughly analyzing footsteps in different situations and making it into a data to utilize it for finding suspect. Criminal investigation technique using footstep should be systemized as shown and explained in Fig. 6. First of all, footstep sound is collected from the crime scene and compare it with list of suspects. After identifying suspects, check subject of the person, gender, identification and personal features from the sound.

At the same time, analyze space, environment and psychological status of the person. We can know how urgent the situation was through this various analysis on the situation. 


\section{CONCLUSION}

There is a saying in Korean that criminals leave their foot marks. It refers to the footstep, footstep sound is a part of foot marks. As we have recording function in CCTV, sound information can be a great data for preventing and investigating crime. Also, this can be obtained easily by recording function or application in smartphone. Therefore, among many sounds as footstep has various information, this will imply a key clue to settling the case if analyzed thoroughly. According to the research result if regularity of footstep sound is analyzed in more details, this will even tell the personal characteristics. This means that it will help increase arresting rate of the criminal if the criminal is an acquaintance. What is more, one can tell environment and location of the person through this analysis. As this is the case, if all those data contained in footstep sound is created into a database, this will be an innovative research for developing footstep sound examination area as one of scientific investigation techniques.

\section{REFERENCES}

Ahn, I.S., 2012. Research on the dramaturgy and initiatives of sound effects for radio drama. Cultural Contents Graduate Sch. Art Chung Ang Univ., 1: 90-96.

Bae, M. and M. Kim, 2013. Professor Bae's Sound Story. Gimm-Young Publishers, Seoul, South Korean,

Buhm, P., Dongki Min and J. Park, 2012. [Comparison of hearing characteristics of sounds form diesel and gasoline engines (In Korean)]. Korean Soc. Mech. Eng., 1: 352-353.
Go, H.W. and Y.H. Kim, 1997. Setting and analysis of awakening control standard for avoiding sleepy driving. Korean Soc. Auton. Veh. Eng., 2: 1171-1176.

Hoon, H.S. and J.B. Myung, 2007. A study on the sound enhancement of concentration. IEICE., 30: 671-672.

Hyung-Jin, P., H. Hyeong-Joo and S. Hyun-Joo, 2007. A study on driver characteristics in a long tunnel using simulator. J. Ergon. Soc. Korea, 26: 89-102.

Jung, J.C. and M.J. Bae, 2007. A study on the classification of amazing sounds. Acoust. Soc. Korea, 26: 57-58.

Kang, M.J. and G.K. Jeong, 2007. [Efficiency improvement about digital evidence investigation in Korea (In Korean)]. J. Korea Contents Assoc., 7: 180-190.

Kyu-Young, C. and K. Yun-Hee, 2014. [Factors affecting smartphone addiction among university students (In Korean)]. J. Korea Acad. Ind. Cooperation Soc., 15: $1632-1640$.

Ryu, H.S. and G.K. Chang, 2004. A study for introduction and practical use of scientific investigation technique of advanced countries: Focusing on scientific reliability and soft scientific analysis. Korean Inst. Criminology Res. Ser., 38: 415-496.

Se-Bin, J., 2014. A study on the development of safety system for the elderly driver. J. Korea Soc. Automot. Eng., 22: 234-240.

Soon-Hee, J., 2015. A study on the relationship between social development and ego resilience of middle school students and smartphone addiction. Master Thesis, Woosuk University, Wanju County, South Korea.

Yoo, H.J., 2016. A study on optimization of sound warning alert for drowsy alert. Intergalactic research Institute for Sound, Korea. 